\title{
UNA VISIÓN COMUNICACIONAL DE LA POLÍTICA EN ECUADOR: RAFAEL CORREA Y SU BICICLETA ${ }^{1}$ A VISION OF COMMUNICATION POLITICS IN ECUADOR: RAFAEL CORREA AND YOUR BICYCLE
}

\author{
María Isabel Punín Larrea \\ Universidad Técnica Particular de Loja \\ San Cayetano Alto s/n. Loja-Ecuador \\ mipunin@utpl.edu.ec
}

\begin{abstract}
Resumen
Este artículo analiza el video oficial de la campaña del Presidente Correa denominado "spot bicicleta", elemento promocional usado en las elecciones seccionales del 2013, toma como referencia de análisis las estructuras fonológicas, gráficas, sintácticas y semánticas.

La pieza con una duración de 3:30 minutos, recuerda el proceso de "Revolución Ciudadana", emprendido por el partido Alianza País (35); y resalta la condición de servicio del Presidente, cuyo eje principal es la Patria.

El discurso gira entorno a la pobreza, la esperanza y el deseo del Presidente de continuar en el poder. Toda la pieza audiovisual está matizada con elementos posicionados en la mente de los ecuatorianos, usados como una estrategia de persuasión.

Palabras claves: Publicidad; Política; Elecciones; Democracia; Rafael Correa.

\section{Abstract}

This article analyzes the official "bicicleta" publicity video for President Rafael Correa's campaign in the Sectional Elections in 2013 by examining its phonological, graphical, syntactic and semantic structures.

The video, which runs for three minutes and 30 seconds, recalls the development of the "Citizens' Revolution" by the Alianza País political party (35); it highlights the President's service to the country, and its core idea is the Homeland.
\end{abstract}

${ }^{1}$ El trabajo se refiere al video promocional del Presidente Rafael Correa, durante su última campaña electoral. La versión tomada para el estudio se encuentra disponible en internet en: http://www.youtube.com/watch?v=iLgiElnQ0j4 
The discourse talks of poverty, hope and the desire of the President to remain in power. The audiovisual content contains elements designed to strike a chord in Ecuadorians, and the strategy is clearly one of persuasion.

Key words: Advertising; politics; elections; democracy; Rafael Correa.

\section{Extended Abstract}

This article analyzes the official "bicicleta" publicity video for President Rafael Correa's campaign in the Sectional Elections in 2013, as an audiovisual resource in which the discourse is designed to persuade and convince its viewers.

The study examines the phonological, graphical, syntactic and semantic structures to reach the critical discourse as proposed by Van Dijk.

The video runs for three minutes and 30 seconds and recalls the development of the "Citizens' Revolution" by Alianza País (35), Ecuador's leading political party. Ecuador was once seen as ungovernable due to the overthrow of several of the country's presidents, but stability has returned in the figure of Rafael Correa who has been in power now for three legislative terms.

The video contains images that highlight the President's service to the country through slogans whose main focus is the Homeland. Other elements typical of advertising campaigns feature, including slogans proclaiming that "The Homeland now belongs to all of us", "The Homeland for all is here to stay"; these are part of a political communication strategy not normally seen in Ecuador.

The study identifies and describes mindsets in the script apparent in the video's discourse and voiceover in order to build a general semantic structure of the video, in which the Presidents appears as a mediatory figure.

The discourse speaks of poverty, hope and the homeland, and the desire of the President to retain power. The video contains elements designed to strike a chord in Ecuadorians, and concludes with a classic "happy ending".

\section{INTRODUCCIÓN: UN COMERCIAL CON EL PRESIDENTE COMO EJE CENTRAL DE LA CAMPAÑA SELECCIONES 2013}

Planificar estratégicamente una campaña electoral requiere la utilización de métodos cuantitativos (que respondan a las preguntas de qué y cuántos) y cualitativos (por qué) (Rúas, 2011: 25). En el último proceso electoral ecuatoriano, celebrado el pasado 17 de febrero del 2014, quienes mejor utilizaron estos métodos fueron los integrantes del partido de Gobierno denominado Alianza País $(A P)^{2}$, partido con un "fuerte discurso antipartidario, y una orga-

${ }^{2}$ Alianza País. Patria altiva y soberana. Listas 35 es un movimiento político que nace el 2006. La propuesta se fundamenta en Socialismo del Siglo XXI o el "Socialismo del Buen Vivir”. Su página oficial es: http://www.movimientoalianzapais.com.ec/ (17/07/2014) 
nización sin una historia previa al ejercicio del poder estatal" (Hernández; Buendía, 2011: 129).

Este artículo tiene como objetivo el análisis de la pieza publicitaria y audiovisual denominada "spot bicicleta", que contiene algunos elementos novedosos para el manejo de la comunicación política en Ecuador, usa recursos de la comunicación 2.0, y apela al uso del discurso como arma de persuasión y convencimiento.

El artículo hace una descripción de carácter semiótico del discurso, tomando la referencia la propuesta denominada: Análisis crítico del discurso (Van Dijk, 2000), esto quiere decir el análisis de las:

1. Estructuras fonológicas

2. Estructuras gráficas

3. Estructuras sintácticas y semánticas

En resumen, el estudio y descripción modelos mentales que se emiten tanto en el guión, como en el discurso (voz en off); la macro estructura semántica, expresada en la condición de mediador del Presidente y además protagonista de la historia.

La imagen del Presidente asoma como una fotografía continua, la fotografía lleva siempre un referente consigo y es literalmente una emanación del referente (Barthes, 1981) donde él es el sujeto autor de la historia, que relata su plan de gestión, matizado por sus sueños e ideales.

Se analiza además el contexto y las relaciones de poder usadas en el video promocional, difundido por el canal de Youtube por EcuaTVmedia. El video tiene una duración de 3:30 minutos, y hasta finales del 2014 registra un total de 28.011visitas, fue producido por Vertigo Films 3 .

Para la musicalización (estructuras fonológicas) se usa poema épico denominado "Patria", cuya letra está atribuida a Manuel María Sánchez y la música de Sixto María Durán. El uso de esta pieza musical no es una decisión improvisada, en el 2007, existió una insinuación por parte del entonces Ministro de Educación Raúl Vallejo ${ }^{4}$, para la escucha de este himno en los establecimientos educativos del país, la melodía que tiene un particular significado de patriotismo para los ecuatorianos y ecuatorianas.

\footnotetext{
${ }^{3}$ Esta productora funciona en la ciudad de Quito, y ha logrado captar importantes proyectos audiovisuales del gobierno, entre ellos la campaña "All you need is Ecuador". Su sitio oficial es: www.vertigosite.com

${ }^{4}$ Aunque la petición del entonces Ministro no llegó a constituirse en un decreto, la acción no estuvo libre de críticas. Aquí una reseña de Diario El Universo es: http://www. eluniverso.com/2007/09/26/0001/18/BA3002F6F3B84E2190D67ED451DCC4D0.html $(10 / 08 / 2014)$
} 
Más tarde, Alianza País realizó algunas modificaciones y lo tomó como el himno oficial del movimiento. En el video en referencia la letra oficial incluye una serie de arreglos con violines y guitarras.

\section{SECUENCIAS DE LA HISTORIA. UN SUEÑO, UNA PATRIA}

El trabajo audiovisual y publicitario, en mención, inicia una escena que evidencia el abandono del poder presidencial de R. Correa, el Presidente deja el Palacio de Carondelet, y asume un rol aparentemente nuevo y refrescante, un ciclista común (Ver fotograma No. 1, 2, 3 y 4) (estructuras gráficas).

El presidente asoma solo, lo cual evidencia otros rasgos de su personalidad que han sido duramente cuestionados "Liderazgo personal y hegemónico del Presidente que actúa como obstáculo para institucionalización" (Panchano, 2010), criticas que no son objetivo de este artículo, pero se citan por formar parte de los rasgos del Presidente, protagonista de la historia, y que marcan la imagen del Presidente en el electorado.

El Presidente está dispuesto a recorrer cada rincón del Ecuador, usando una bicicleta. La prominencia de la imagen personal del Presidente apela a la credibilidad del candidato, es uno de los recursos de la comunicación política, y con él "la competencia y la confiabilidad del candidato" (Petit \& Cilimbini, 2009), mientras recorre sus obras, resalta sus logros, las escenas son una acción más de "activismo estatal" (Fiss, 1997) y de la consolidación de un "estado comunicador" (Rincón, 2010).

La pieza expresa un arte de "puesta en escena" y su eficacia específica radica en la capacidad de los gobernantes y jefes para generar emociones y sentimientos (Bustamante, 2002). En las tomas se aprecia además el uso de elementos oficiales como la banda presidencial, el Palacio de Carondelet (casa oficial del Mandatario), armonizado por un discurso ideológico, que considera la relación sociedad-individuo (Knorr-Cetina; Cicourel, 1981), y su derecho pero a su vez un poder, el voto.

En este escenario Correa inicia con su propia voz a comentar su sueño (estructuras sintácticas/semánticas), al que denomina: "el sueño ecuatoriano", pero también es una oportunidad para recordar frases usadas de manera recurrente en sus discursos anteriores como: "manos limpias, mentes lucidas y corazones ardientes"

${ }^{5}$ En este link se puede observar la versión oficial del discurso de R. Correa (Informe a la Nación 2014: https://www.youtube.com/watch?v=wMYhTzU83-w\&feature=youtu.be\&list= UUn2XiuAROvRcqscSI2Ni-6A La frase se volvió a usar en la noche cultura en Barcelona/ España a inicios del 2014 https://www.youtube.com/watch?v=45t9UXKcS_Y\&list=UUn2Xiu AROvRcqscSI2Ni-6A 
Con esta introducción Correa Delgado echa mano de la retórica clásica que sugiere el uso de los argumentos y de las emociones, como camino seguro para convencer al electorado "La imagen ya no ilustra a la palabra; es la palabra lo que se convierte estructuralmente en un parásito de la imagen" (Barthes, 1981: 21).

Es importante para lograr una mayor contextualización del tema revisar el plan de gobierno (eje de su estrategia) documento en el cual se cita lo siguiente: "Es nuestro deber desterrar el hambre y la pobreza. Mientras subsista una sola injusticia en nuestra Patria, allí estaremos, con un vendaval de amor y ternura siempre con el oído atento a la demanda y a la voz de los humildes y desampa-

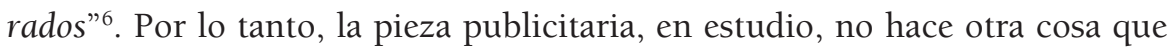
reforzar lo dicho en los discursos magistrales en los primeros períodos presidenciales, que han sido difundidos de manera sistemáticas en los medios de comunicación.

Por ello, al inicio de la pieza audiovisual se destaca el tema que seguramente preocupa al electorado ecuatoriano: la pobreza, lo cual también puede llevarnos a un discurso de ideologías contradictorias, por un lado, la igualdad y por otro la libertad económica (Tetlock, 1989).

Según un informe del Cepal (2012), Ecuador tuvo una reducción de los índices de pobreza que pasaron del 35,3\% al 32,2\% entre el 2011 y el 2012, pese a ello, de la pobreza, es un tema de consideración mayor en el vídeo en referencia.

La pieza en estudio también deja espacio para otro de los factores que están presentes en el imaginario popular: la violencia. Por ello, el combate a la inequidad se realiza con "con un vendaval de amor y ternura", lo cual también podría expresar de manera velada como " tolerancia", que se aprecia como un valor sociocultural positivo de "apariencia" (Van Dijk, 1984)

La última frase "siempre con el oído atento a la demanda y a la voz de los humildes y desamparados", se refiere al desencanto del sistema democrático y al anhelo de establecer una verdadera democracia representativa, actitud que podría tener una variante en relación a su discurso de campaña (2006/2007), en la cual se usó como un elemento "una correa" (Ver Foto No.1), sin que ello implique un distanciamiento del ciudadano común, sino por el contrario un hombre que impone justicia.

\footnotetext{
${ }^{6}$ Cf. Programa de Gobierno 2013 - 2017 disponible en internet en: http://www.movi mientoalianzapais.com.ec/index.php?option $=$ com_content\&view=article\&id=10:plan-degobierno-2013-2017\&catid=22\&Itemid $=126 \&$ tmpl=component $\&$ print $=1 \&$ layout $=$ default\&page $=$ consultado el 3 de julio de 2014 .
} 


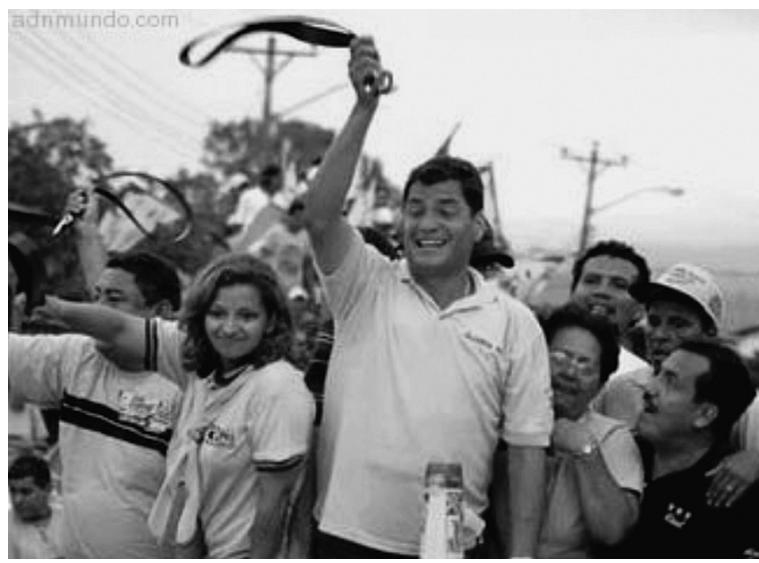

Fuente: www.ecuaword.com (Foto n. ${ }^{\circ} 1$ )

Pero ¿es este un uso «comercial» de las necesidades populares? O, en realidad, ¿es una manera «democrática» de formular un plan de gobierno, atendiendo a las necesidades de la mayoría? aunque las preguntas no son parte de este análisis, quedan planteadas para el debate, por ser elementos de persuasión usados por el mandatario.

La estrategia audiovisual, se usa varios elementos. Las imágenes representan una persona capaz de dejar el poder (ver fotograma n. ${ }^{\circ} 1$ ), vestirse como el pueblo (ver fotograma . $^{\circ}$ 2) porque lleva el país en el corazón (ver fotograma n. ${ }^{\circ}$ ), dejar su comodidad (entiéndase Palacio Presidencial) (ver fotograma n. ${ }^{\circ}$ ) y salir a ver la realidad del país (ver fotograma n. ${ }^{o}$ 5), usando para ello las tres estructuras recomendadas por Van Dijk y referencia de análisis del presente estudio.

Es decir alguien que usa el poder para el servicio. Entonces, esta primera parte del video principal de la campaña de AP, es coherente con su estrategia vemos a un mandatario que, en el fondo, trata de representar democráticamente a sus mandantes.

Las escenas muestran un hombre fuerte y el audio nos va hablando de «luchas», «golpes», «traiciones», con el fondo musical sinfónico ya comentado. El video originó la difusión de una pieza relacionada con elementos de la publicidad negativa ${ }^{7}$, cuyo protagonista es el hijo del ex presidente Dalo Bucaram, uno de los líderes visibles de la oposición en el país. Los elementos audiovisuales de la pieza de Bucaram representan la antítesis de los usados por el Presidente.

${ }^{7}$ El video en referencia se puede visualizar en el siguiente link: https://www.youtube. com/watch?v=T-40XsREczk 


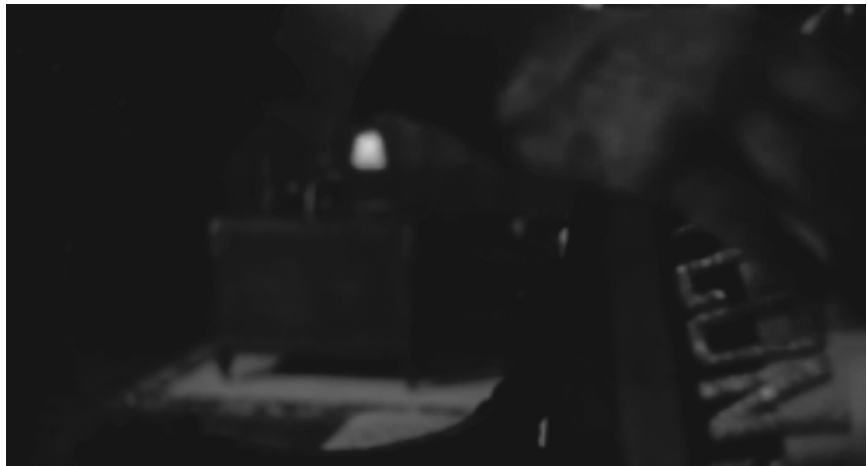

Fotograma.$^{\circ} 1$

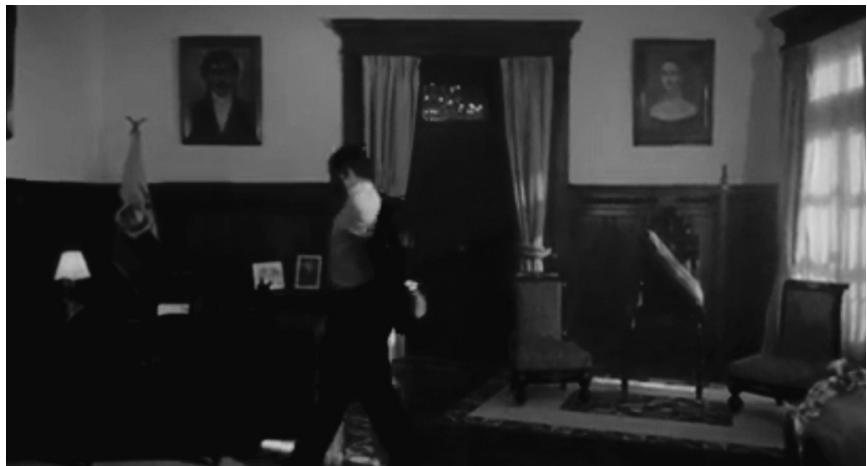

Fotograma n. ${ }^{\circ} 2$

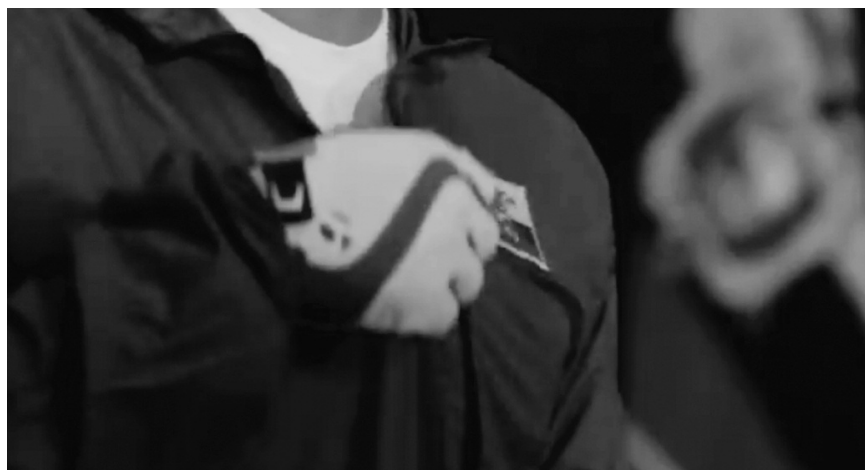

Fotograma n. ${ }^{\circ} 3$ 


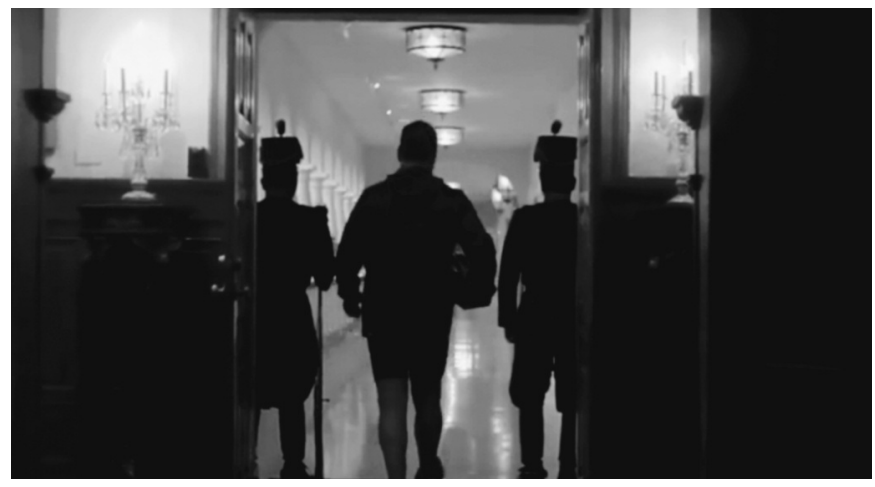

Fotograma n. ${ }^{\circ} 4$

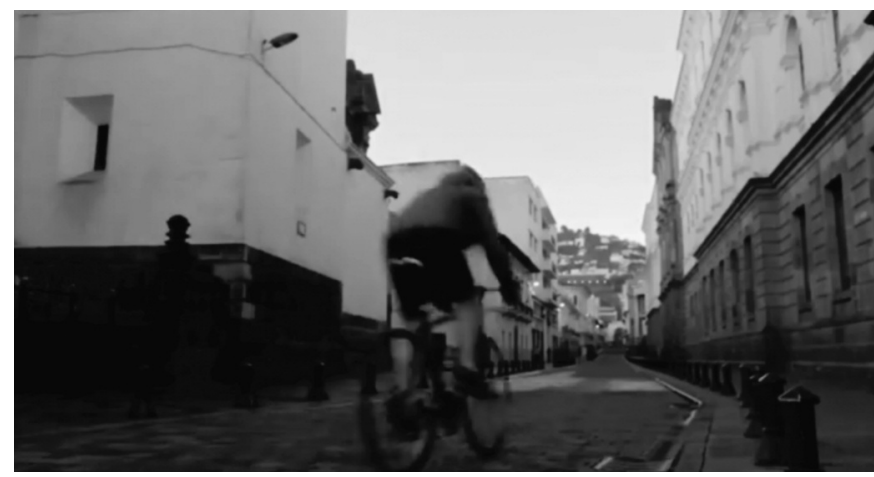

Fotograma n. ${ }^{\circ} 5$

Más adelante el video logra configurar una especie de «superhombre» dispuesto a pelear por todos, enfrentando retos importantes y enemigos poderosos, en una clara alusión a los grupos de poder que gobernaron al Ecuador, recordando la crisis de gobernabilidad del país, que en palabras del Presidente de puede resumir con "el fin de larga y oscura noche neoliberal".

El tema de la pobreza, vuelve a ser un tema recurrente en el spot:

Nuestro "superhéroe", o el superhombre de masas (Eco, 1995), que en su inseparable bicicleta empezó recorriendo la sierra ha llegado a lo que parecería ser el litoral ecuatoriano, por grandes carreteras construidas como parte de su plan de gobierno. Ahora, queda todavía el problema de la pobreza. No es un tema extremo, pero lo recuerdan dos hombres, uno sentando a la vera del camino sin camiseta y otro, en el fondo, parado frente a una humilde casa (fotograma n. ${ }^{\circ} 6$ ), lo ven pasar aparentemente esperanzados de lo que pueda hacer en su nuevo mandato presidencial. Entonces, el video muestra nuevamente coherencia, ante una pobreza que todavía está presente pero que debe combatirse, 


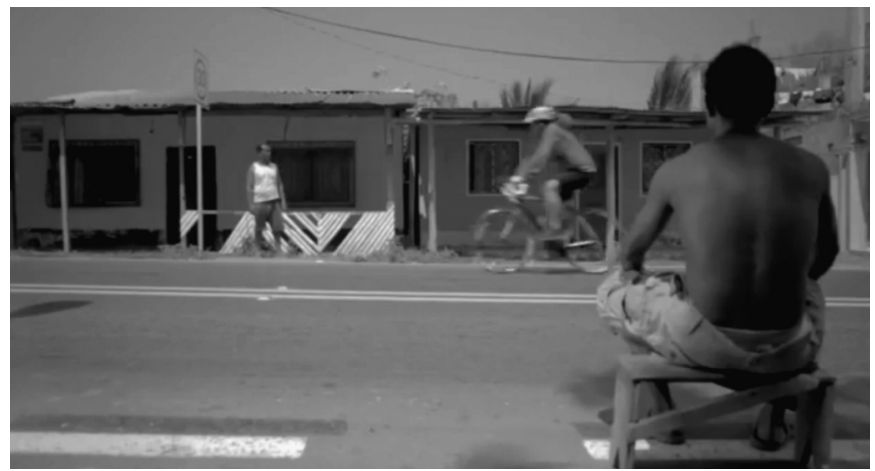

Fotograma n. ${ }^{\circ} 6$

como lo demostramos usando información del Cepal. Claro, este combate, entiéndase gestión presidencial, deber hacerse con «amor y ternura» y nada representa mejor estas dos cosas que los niños (fotograma $n .^{\circ} 7$ ).

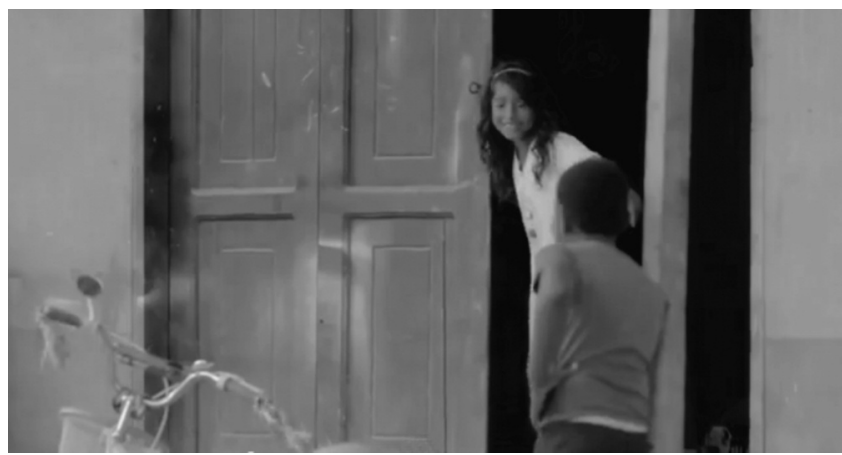

Fotograma n. ${ }^{\circ} 7$

Son estos niños que ven pasar a su superhéroe (ver fotograma n. ${ }^{\circ} 7$ ), toman sus bicicletas (ver fotograma 8) y lo acompañan, no lo siguen, evitando así la sensación de jerarquía y poder (ver fotograma 9).

Al televidente, que seguramente ha tenido formación cristiana, este hecho le recuerda el famoso pasaje bíblico «Dejad a los niños, y no les impidáis que vengan a mi» (Mateo 19: vr. 14) se ve un mandatario sonriente y que tiene como sus compañeros (¿y guardianes?) a los niños, por ello, durante toda la escena los niños están siempre a su lado, lo cual también responda a una macro estructura semántica, sobre todo para la población ecuatoriana mayoritariamente católica. También puede interpretarse a la luz del siguiente pasaje bíblico «Mirad que no menospreciéis a uno de estos pequeños; porque os digo que son sus ángeles en los cielos» (Mateo 18: vr. 10). 


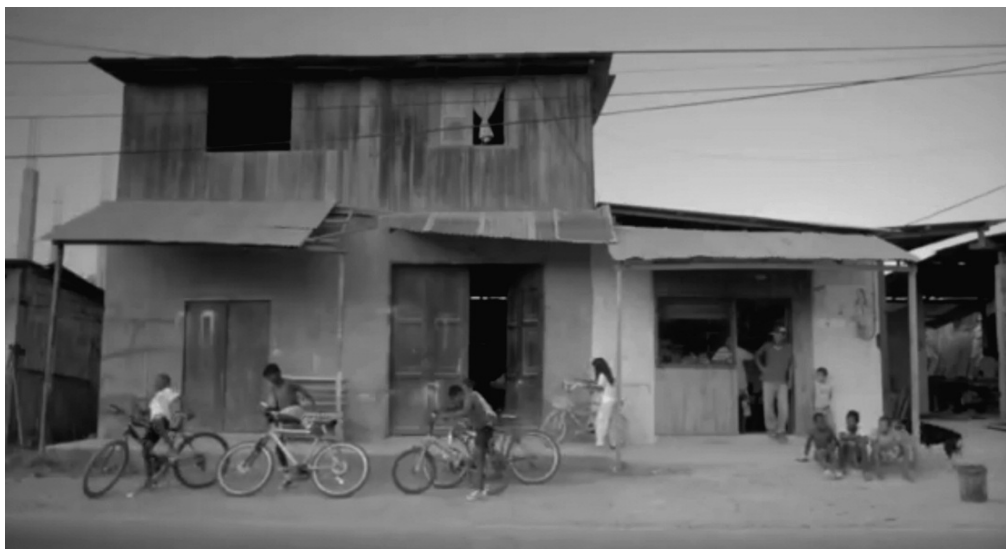

Fotograma n. ${ }^{\circ} 8$

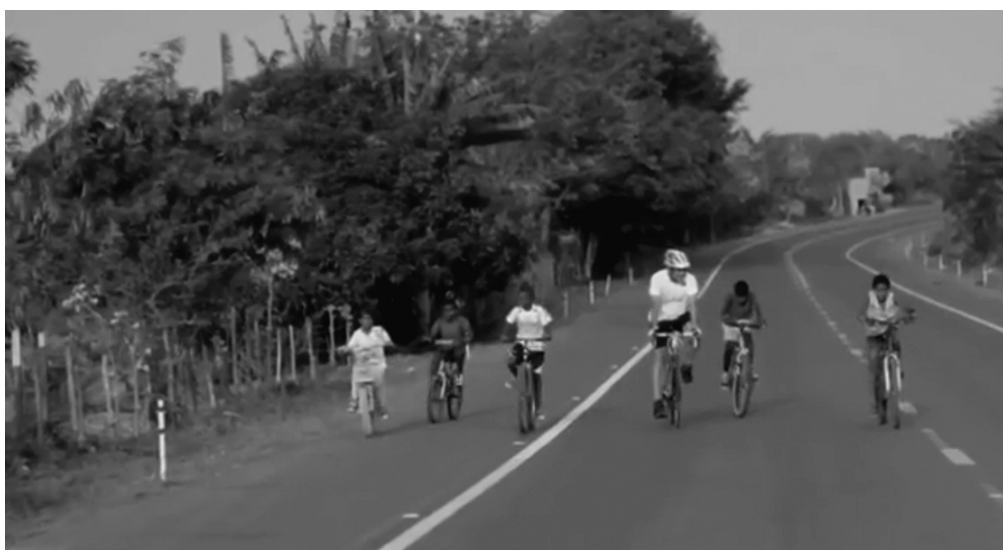

Fotograma n. ${ }^{\circ} 9$

Es un superhombre de carne y hueso. Merece un descanso junto a la naturaleza, nótese el verde réflex de la camisa, en clara sintonía con los colores de su partido, que han sido usados a lo largo de los procesos de campaña. Nada mejor para representar esto que la siguiente escena:

El hombre toma un sorbo de agua en lo que parece una playa solitaria (ver fotograma n. ${ }^{\circ} 10$ ). El protagonista se quita el casco, al fondo se ven seis humildes embarcaciones de pescadores (ver fotograma n. ${ }^{\circ} 11$ ), con los que se va a seguir su recorrido (ver fotograma n. ${ }^{\circ}$ 12). La selección del rol y de los personajes en escena no es improvisada, considerando que "la sociedad real se desinteresa de la clase política sin perderse el espectáculo"(Baudrillard, 2000: 96), como una vía efectiva para llegar al electorado. 


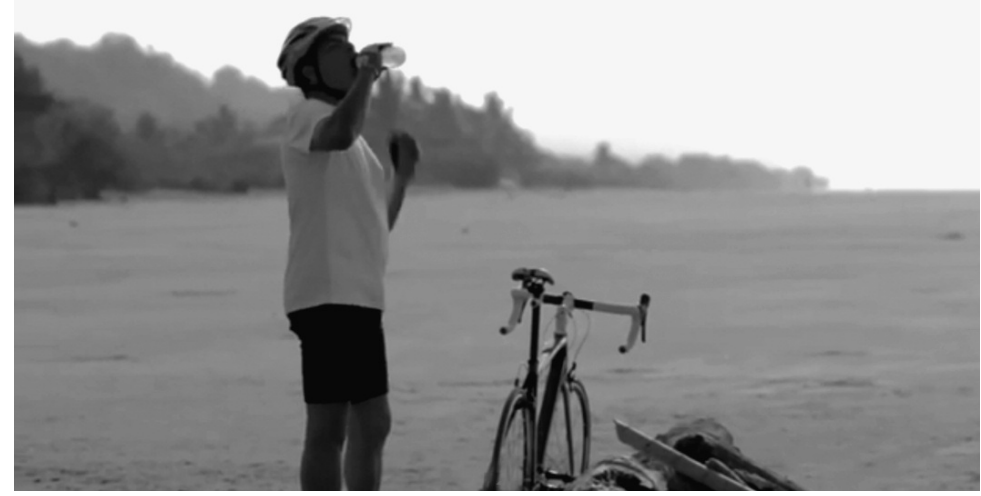

Fotograma n. ${ }^{\circ} 10$

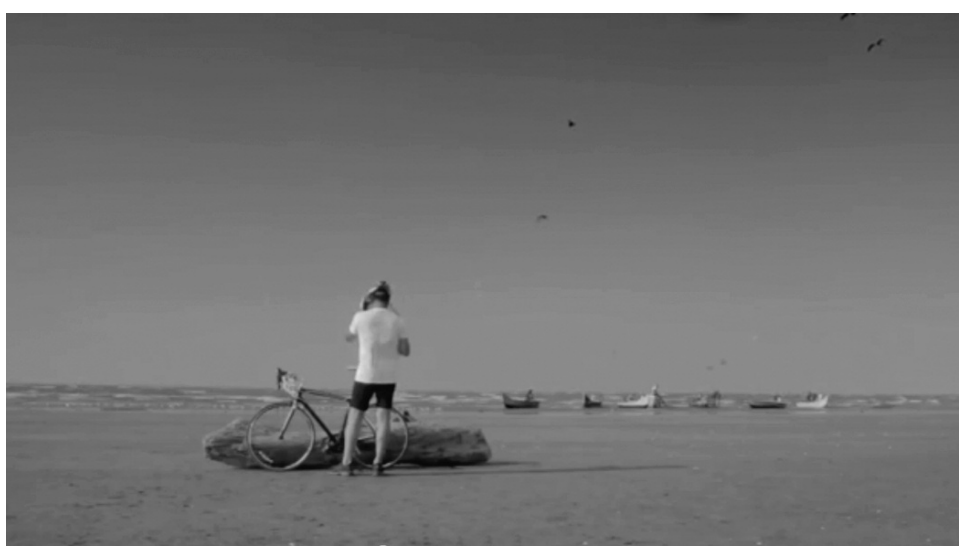

Fotograma n. ${ }^{\circ} 11$

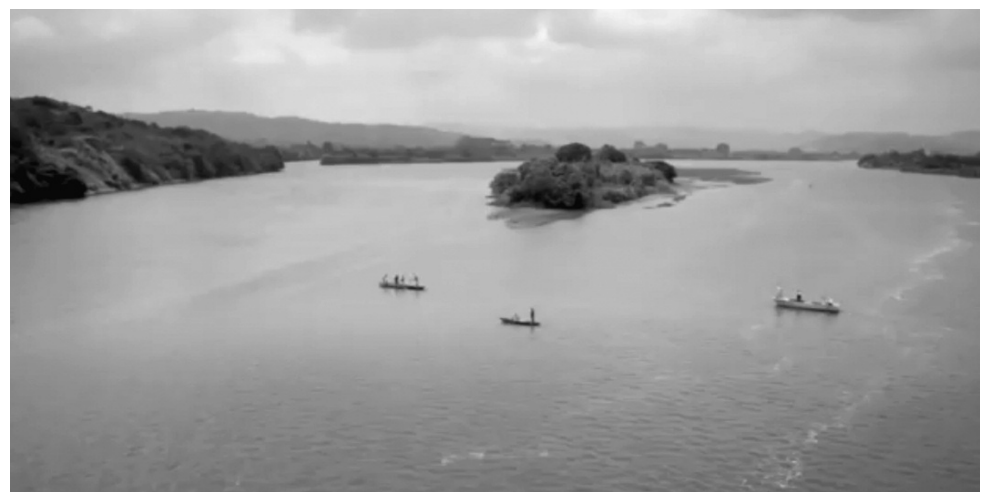

Fotograma n. ${ }^{\circ} 12$ 


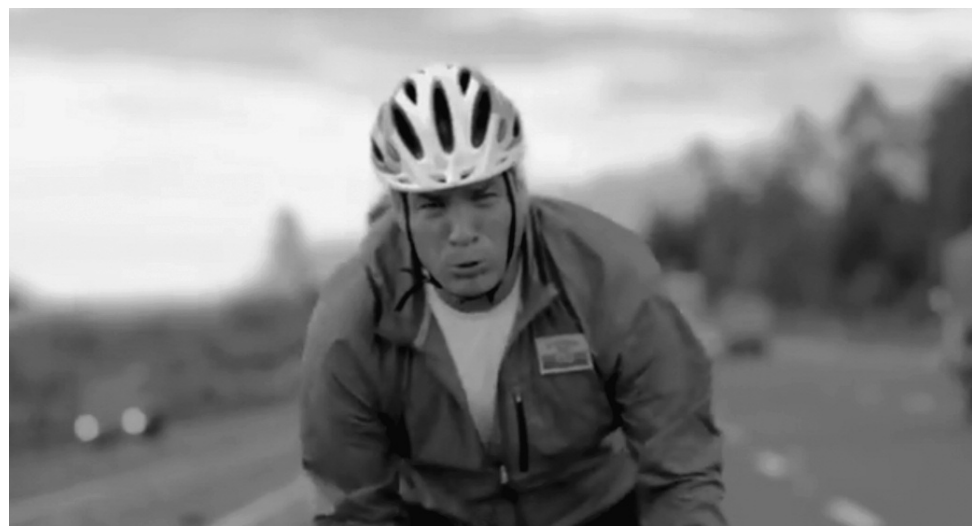

Fotograma n. ${ }^{\circ} 13$

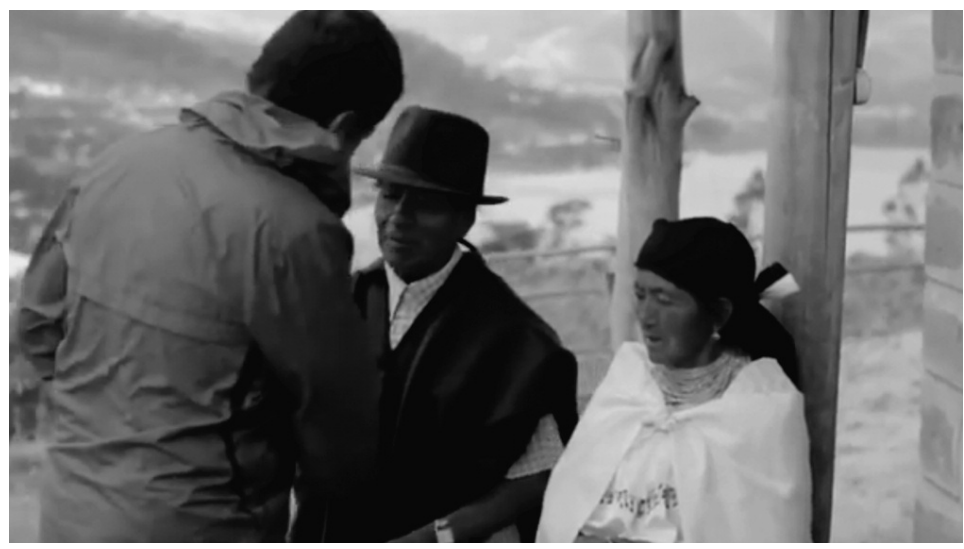

Fotograma n. ${ }^{\circ} 14$

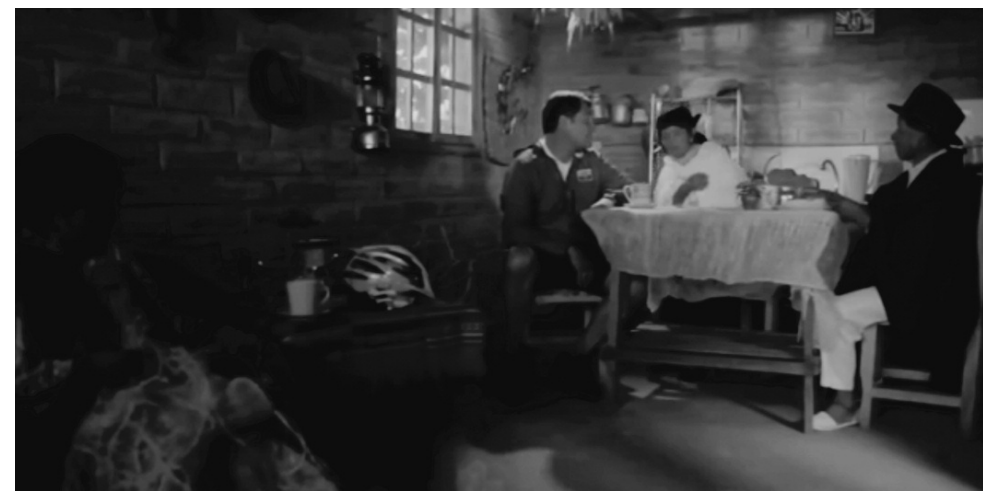

Fotograma n. ${ }^{\circ} 15$ 
Con mucho esfuerzo físico (ver fotograma n. ${ }^{\circ} 13$ ), llega hasta la alta serranía nacional, saluda con indígenas ancianos (isabios?), pobres pero dignos, su casa ya no es una humilde choza de barro sino una vivienda construida con ladrillo (ver fotograma n. ${ }^{\circ} 14$ ). Entra, y sentados a la mesa, conversan en quichua sobre lo que parecería ser la problemática del país (ver fotograma ${ }^{\circ}{ }^{\circ}$ 15), que bien puede relacionarse con los postulados del "Buen Vivir" (Sumak Kawsay), es decir imaginario (ideal de vida) (Avila, 2014).

Entendemos el "Buen Vivir" como un concepto en construcción (Gudynas; Acosta, 2011), que se encuentra reflejado a lo largo de la Constitución Ecuatoriana. El Buen Vivir forma parte de una larga búsqueda de alternativas de vida fraguadas en el calor de las luchas populares, particularmente indígenas, desde mucho antes de que acceda al poder político el presidente Rafael Correa (Acosta, 2010: 7).

Con ello se cumple la última parte del postulado de Alianza País: «con el oído atento a la demanda y a la voz de los humildes y desamparados». El hecho que el Presidente habla quichua, tiene sentido si nos remitimos a la Constitución Ecuatoriana (2009). Artículo No. 1, que considera a este idioma junto al shuar, como lenguas oficiales de los indígenas.

En resumen, niños, pescadores y los indígenas, son usados como los buenos" dentro del discursos ideológico de grupo (Van Dijk, 1996), elemento que no es ajeno del lenguaje audiovisual, en general.

\section{CONCLUSIONES: UN FINAL FELIZ SIEMPRE}

El video está marcado por el uso armónico de las estructuras fonológicas, gráficas, sintácticas y semánticas, cuyo objetivo máximo es el apoyo y la consolidación del movimiento y los postulados de Alianza País. Aunque el Presidente no fue candidato en esta ocasión, usó su imagen como refuerzo para las candidaturas seccionales de todo el país.

El video tiene un «happy end», nuestro héroe deja la banda que se quitara al inicio del spot, y que representa el poder constitucional de la presidencia, sobre una silla en la casa de los ancianos (ver fotograma n. ${ }^{\circ} 16$ ). El poder es del pueblo, no de él, lo que también justifica el uso de otros individuos a lo largo de toda la pieza.

Se trata de un video coherente con sus eslóganes en el que las ideas se centran en la lucha contra la inequidad y la capacidad del candidato para enfrentar el reto, compromiso que está constantemente siendo reforzado con la postura discursiva del presidente, dispuesta a combatir la pobreza sin violencia, aunque los resultados en las urnas no fueron del todo positivos. 


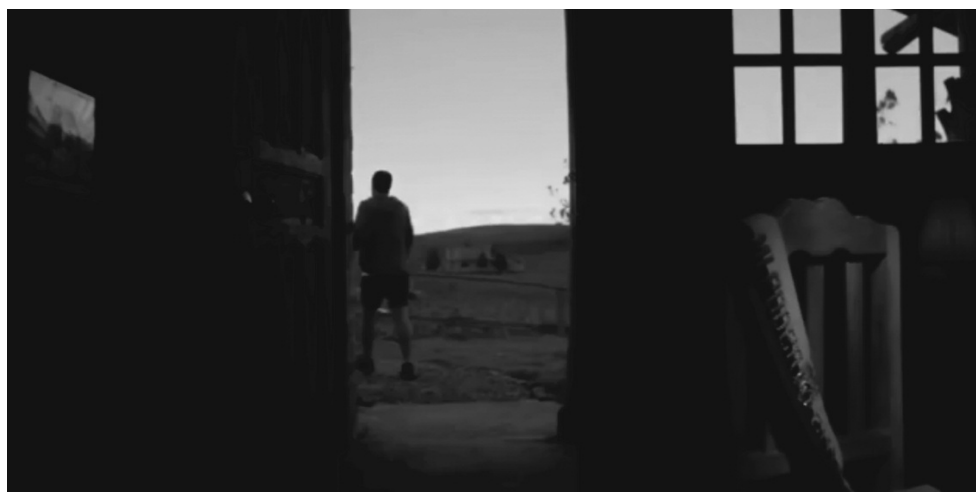

Fotograma n. ${ }^{\circ} 16$

Existe una variante significativa entre el inicio del proyecto política liderado por Correa y el recurrente uso del slogan: "La patria ya es de todos" con nueva variante con la que se cierra el discurso escénico "La patria volvió para siempre", que asoman como elementos de convencimiento y persuasión.

Este análisis podría continuar y, muy probablemente, encontraríamos más elementos coherentes entre el ideario de AP y su realización publicitaria en campaña y otras propias del espectáculo televisivo.

\section{BIBLIOGRAFÍA}

Acosta, A. (2010). "El buen vivir en el camino del post-desarrollo. Una Lectura desde la Constitución de Montecristi". Policy Paper 9. Friedrich Ebert Stiftung. Pp. 7. Disponible en: http://cadtm.org/IMG/pdf/El_Buen_Vivir_en_el_camino_del_ post-desarrollo-_Una_lectura_desde_la_Constitucion_de_Montecristi.pdf (Fecha de consulta 22-12- 2014).

Avila, J. (2014). "El enfoque del buen vivir como una visión colectiva". OBETS. Revista de Ciencias Sociales. Vol. 9, n. ${ }^{\circ}$ 1, 2014; pp. 43-72. DOI: 10.14198/OBETS 2014.9.1.02. Disponible en: http://dx.doi.org/10.14198/OBETS2014.9.1.02 | http: //hdl.handle.net/10045/39557 (Fecha de consulta 12-11- 2014).

Barthes, R (1981). Camera Lucida. Hill and Wand. New York Baudrillard, J (2000). Pantalla total. Anagrama. Colección de argumentos.

Biblia (s/n) Mateo 19: versículo14. Nueva versión internacional Biblia (s/n) Mateo 18: versículo10. Nueva versión internacional Cepal (2013). "Panorama Social de América Latina". Naciones Unidas Cepal. Disponible en: http://www.cepal.org/publicaciones/xml/9/51769/PanoramaSocial 2013.pdf) (Fecha de consulta 10-05-2014).

Bustamante, F (2002). La cultura política y ciudadanía en el Ecuador. Antología Democracia, Gobernabilidad y Cultura política. SERIE: Antología CCSS. Disponible 
en: http://www.plataformademocratica.org/Publicacoes/183.pdf (Fecha de consulta 10-12-2014).

Eco, U. (1995). El superhombre de masas. Barcelona. Lumen.

Fiss, O. (1997). Libertad de expresión y estructura social. México. Distribuciones Fontamara.

Gudynas E; Acosta, A. (2011). "El buen vivir o la disolución de la idea de progreso" En: La medición del progreso y del bienestar. Propuestas desde América Latina. Foro consultivo, científico y tecnológico. A.C México DF. Disponible en: http://www. gudynas.com/publicaciones/capitulos/GudynasAcostaDisolucionProgresoMx1lr. pdf (Fecha de consulta 20-12- 2014).

Hernández V; Buendía F (2011). "Ecuador: avances y desafíos de Alianza País”. Revista Nueva Sociedad No. 234. Julio-Agosto. Disponible en: http://nuso.org/upload/ articulos/3790_1.pdf (Fecha de consulta 19-12- 2014).

Knorr- Cetina, K. Cicourel (Eds) (1981). "Advances in social theory and methodology: towards an integration of micro and macrosociologies". London. Routledge and Kegan Paul.

Panchano, S. (2010). "Ecuador: El nuevo sistema político en funcionamiento". Revista de Ciencia Política. Volumen 30. No.2. 297-317. Disponible en: http://www.scielo. cl/scielo.php?pid=S0718-090X2010000200007\&script=sci_arttext (Fecha de consulta 15-11- 2014).

Petit \& Cilimbini, A.L (2009). "Medios y Tecnologías de la Información y la Comunicación. Socialización y Nuevas Apropiaciones”. Argentina: Editorial: Brujas.

Rincón, O y otros (2010): “¿Por qué nos odian tanto? Estado y medios de comunicación en América Latina". En Centro de Competencias en Comunicación para América Latina. Disponible en: http://library.fes.de/pdf-files/bueros/c3-comunicacion/ 07475.pdf (Fecha de consulta 22-12- 2014).

Rúas, J. (2011). Manual del candidato electoral. Cómo no perder las elecciones. Catara Madrid. Pp. 25.

Tetlock, P. (1989). Structure and function in political belief systems. In A.R. Pratkanis, S.J. Breckler, \& A.G. Greenwald (Eds.), Attitude Structure \& Function

TA Van Dijk. (1984). Prejudice in Discourse. An Analysis of Ethnic Prejudice in Cognition and conversation.

TA Van Dijk. (1996). "Análisis del discurso ideológico. Versión No. 6. Unam México". Disponible en: http://segundaslenguaseinmigracion.com/L2ycomptext/Anlisisi deolgico.pdf (Fecha de consulta 15-09- 2014).

TA Van Dijk. (2000). El discurso como estructura y proceso. Barcelona: Editorial Gedisa.

MARIA ISABEL PUNÍN es PhD. en Comunicación y Periodismo por la Universidad Santiago de Compostela, Diplomado Superior Experto en Gestión y Calidad Universitaria. Universidad de Sevilla. Licenciada en Ciencias de la Comunicación Social. Universidad Católica del Azuay- Ecuador. Ex directora 
de la titulación de Comunicación Social, Modalidad Abierta y Modalidad Presencial. Docente investigadora del Departamento de Ciencias de la Comunicación y Profesor titular de la materia de Géneros Periodísticos. Universidad Técnica Particular de Loja. Integrante del equipo académico para el proceso de evaluación y acreditación ante el Consejo Latinoamericano de Altos Estudios de Periodismo (CLAEP) de la Titulación en Comunicación Social de la UTPL.

Recibido: 20/09/2014

Aceptado: 30/12/2014 